\title{
Comparing three scheduling methods using BIM models in the Last Planner System
}

DOI 10.1515/otmcj-2016-0024

Received September 19, 2017; accepted November 24, 2017

Abstract: This article presents strategies for teaching scheduling methods such as takt-time, flowlines, and point-to-point precedence relations (PTPPRs) using building information modeling (BIM) models in the Last Planner System. This article is the extended version of the article entitled "Teaching Takt-Time, Flowline and Point-to-point Precedence Relations: A Peruvian Case Study," which has been published in Procedia Engineering (Vol. 196, 2017, pages 666-673). A case study is conducted in final year students of civil engineering at the Pontifical Catholic University of Peru. The mock-up project is an educational building that has high repetitive processes in the structural works phase. First, traditional tools such as Excel spreadsheets and 2D drawings were used to teach production system design with takt-time, flowlines, and PTPPR. Second, 3D and 4D models with Revit 2016 and Navisworks 2016 were used to integrate the previous schedules with a BIM model and to identify its strengths and weaknesses. Finally, Vico Office was used for the automation of schedules and comparison of the methods in 4D and 5D. This article describes the lectures, workshops, and simulations employed, as well as the feedback from students and researchers. The success of the teaching strategy is reflected in the survey responses from students and the final perceptions of the construction management tools presented.

Keywords: Last Planner System, BIM, flowline, point-topoint precedence relations, takt-time, teaching

\footnotetext{
*Corresponding author: Xavier Brioso, Construction Management \& Technology Reserarch Group (GETEC), Pontifical Catholic University of Peru, Av. Universitaria 1801, Lima 32, Peru, Email: xbrioso@pucp.edu.pe Danny Murguia, Pontificia Universidad Catolica del Peru, Email: dmurguia@pucp.pe

Alonso Urbina, Pontificia Universidad Católica del Perú, Email: aurbina@pucp.pe
}

\section{Nomenclature}

\author{
BIM building information modeling \\ CPM critical path method \\ LBMS location-based management system \\ LOB line of balance \\ LPS Last Planner System \\ TTP takt-time planning \\ LSM linear scheduling method \\ MEP mechanical, electrical, and plumbing \\ PDM precedence diagram method \\ PTPPR point-to-point precedence relations \\ VPM vertical production method \\ PPC percentage of plan completed \\ AoA activity on arrow
}

\section{Introduction}

Construction projects need a comprehensive production system to improve flow operations in the field. It is argued that the traditional critical path method (CPM) damages the flow as it only models activities and durations. Consequently, it generates a great deal of waste during the construction process (Koskela 1992). As such, scheduling methods should consider the location as a resource that must be explicitly modeled (Dave et al. 2015). Takttime, flowlines, and point-to-point precedence relation (PTPPR) are alternative scheduling methods in the construction management (Brioso et al. 2016). These scheduling methods have been found to be compatible with the different project management systems (Brioso 2015a). The aims of this article are to (1) present strategies for teaching the integration of these scheduling methods in construction management and (2) compare and contrast student's learning experience of such methods. The research strategy used here is the case study at the School of Civil Engineering at the Pontifical Catholic University of Peru (PUCP). 


\section{The Last Planner System}

The Last Planner System (LPS) is a production planning system designed to produce predictable work flow and rapid learning in programming, design, construction, and commissioning of projects (Lean Construction Institute 2016). LPS was created by Glenn Ballard in the early 1990s for project production control. Production control was thought to be a missing piece in the otherwise complete project management toolkit, which was dominated by project control (Ballard 2000). LPS merges two sides of the construction management: first, the project control that sets and monitors project's cost and schedule targets and second, the production control that develops strategies to accomplish those targets (Ballard and Tommelein 2016).

The key development of the LPS is the workflow reliability of construction projects. LPS states that good planning occurs when obstacles that have occurred in the construction industry are overcame, such as (1) planning is not considered as a system, but it is based on the abilities and talents of the professional in charge of scheduling; (2) the performance of the planning system is not measured; and (3) the mistakes in scheduling are not analyzed, and the causes of them are not identified (Ballard 2000). Thus, LPS aims to reduce the gap between WILL (planned) and DID (executed).

LPS consists of five elements: (1) master scheduling (what should be done and when and by whom): setting milestones and strategy and identification of long lead items; (2) phase pull planning (schedule tasks so they can be done): specification of handoffs and identification of operational conflicts; (3) make work ready planning (schedule tasks so they can be done): look ahead planning to ensure that work is made ready for installation and re-planning as necessary; (4) weekly work planning (what will be done): commitments to perform work in a certain manner and a certain sequence; (5) learning (compare did to will): measuring percentage of plan completed (PPC), deep dive into reasons for failure, developing and implementing lessons learned (Ballard 2000; Lean Construction Institute 2016). LPS is based on the idea that all planning is a forecast and forecasts are always wrong (Ballard 2000).

The most popular scheduling methods in the LPS are takt-time planning (TTP) and flowlines. TTP aims to reduce the variability in the downstream processes by pacing the production rate of standard activities across right-sized zones, which could vary on distinct work phases. The sequence of activities must be determined and achieved according to the duration and the crew sizes (Linnik et al. 2013). Meanwhile, the flowline method is a graphical representation of the location-based management system (LBMS), which transforms quantities in locations and productivity information to reliable durations, makes buffers explicit, and forecasts future performance based on historical trends and alarms of future production problems (Seppänen et al. 2010). These methods are compatible and can be aligned with the LPS (Seppänen et al. 2010; Frandson et al. 2013; Murguía et al. 2016).

\section{Scheduling methods: takt-time, flowline, and point-to-point precedence relations}

\subsection{Takt-time}

"Takt" is a German word that refers to the regularity with which something gets done (Frandson et al. 2013). "Takt-time is the unit of time in which a product must be produced (supply rate) in order to match the rate at which that product is needed (demand rate)" (Tommelein 2017). In the manufacturing industry, takt-time could be in seconds, minutes, hours, days, or weeks. However, the construction industry is different, and its takt-times could be defined in hours, days, or weeks. The amount of resources in the desired constant flow must be calculated to make sure that the flow can occur in the selected takt-time. In Latin American countries like Peru, the TTP is referred to as "activity train" (Brioso 2011). On projects based on the LPS, the activity train (constant production flow) is designed using zones in which daily activities will be executed (one-day takt). Figure 1 shows an example of the division in a typical slab (four zones), and Figure 2 shows the takt-time schedule of the structural works using the previous sectorization and one-day takt-time.

\subsection{Flowlines}

Linear project scheduling always represents a major challenge to project managers (Agrama 2011). The linear scheduling method (LSM) is typically used to schedule horizontal repetitive projects, while the vertical production method (VPM) is used to schedule vertical repetitive projects (Agrama 2011). Kenley and Seppänen (2010) state that the flowline method is a graphical representation very similar to the line of balance. For this reason, both are most often confused as they use very similar mathematics. Nevertheless, the representation has a major difference. 


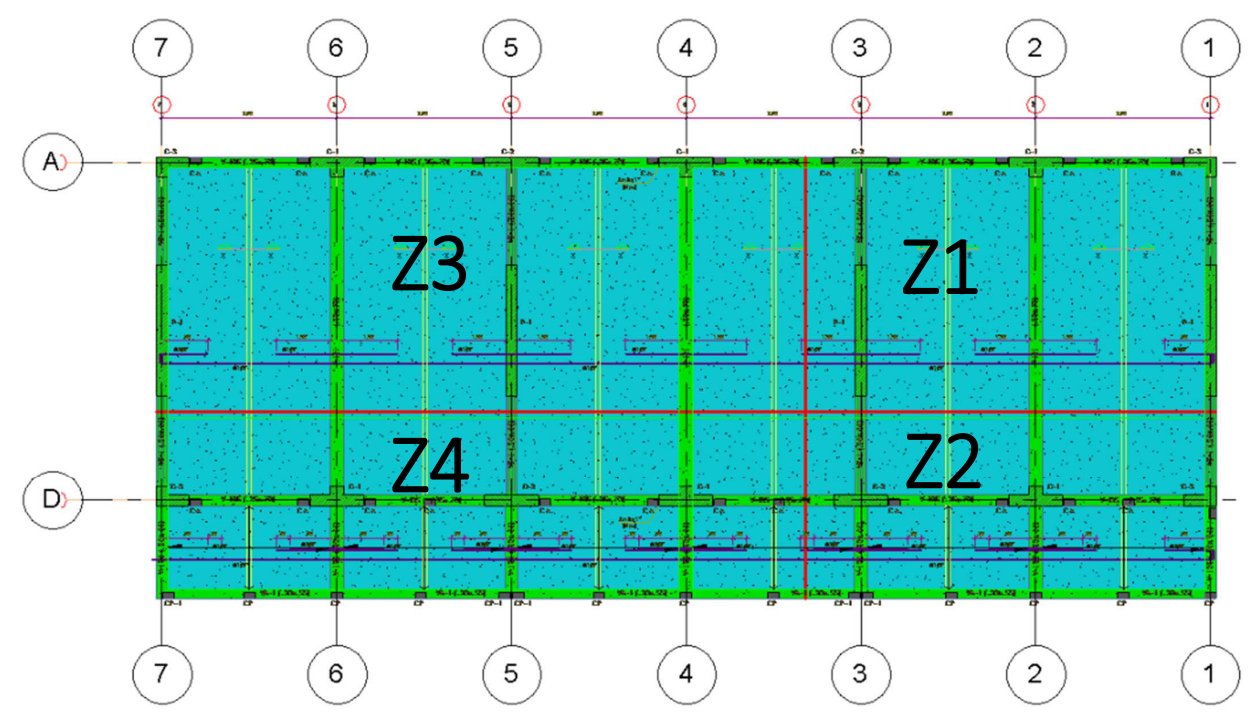

Fig. 1: Sectorization of structural works.

\begin{tabular}{|c|c|c|c|c|c|c|c|c|c|c|c|c|c|c|c|}
\hline \multicolumn{16}{|c|}{ TAKT-TIME 4 ZONES } \\
\hline \multirow{2}{*}{ DAYS } & Mon & Tue & Wed & Thu & Fri & Mon & Tue & Wed & Thu & Fri & Mon & Tue & Wed & Thu & Fri \\
\hline & 1 & 2 & 3 & 4 & 5 & 8 & 9 & 10 & 11 & 12 & 15 & 16 & 17 & 18 & 19 \\
\hline \multicolumn{16}{|l|}{ TASKS } \\
\hline \multicolumn{16}{|l|}{ Structuring Phase } \\
\hline Vertical Rebar & Z1-S1 & $\mathrm{Z2-S1}$ & Z3-S1 & Z4-S1 & Z1-S2 & $\mathrm{Z2}-\mathrm{S2}$ & Z3-S2 & Z4-S2 & $\mathrm{Z1} 1 \mathrm{-S3}$ & Z2-S3 & Z3-S3 & Z4-S3 & & & \\
\hline Vertical Piping Installation & Z1-S1 & Z2-S1 & Z3-S1 & Z4-S1 & Z1-S2 & $\mathrm{Z2}-\mathrm{S} 2$ & Z3-S2 & Z4-S2 & Z1-S3 & Z2-S3 & Z3-S3 & Z4-S3 & & & \\
\hline Vertical Electrical Installation & Z1-S1 & Z2-S1 & Z3-S1 & Z4-S1 & Z1-S2 & Z2-S2 & Z3-S2 & Z4-S2 & Z1-S3 & Z2-S3 & Z3-S3 & Z4-S3 & & & \\
\hline Vertical Formwork & Z1-S1 & Z2-S1 & Z3-S1 & Z4-S1 & Z1-S2 & Z2-S2 & Z3-52 & Z4-S2 & Z1-S3 & Z2-S3 & Z3-S3 & Z4-S3 & & & \\
\hline Vertical Concrete Pouring & Z1-S1 & Z2-S1 & Z3-S1 & Z4-S1 & Z1-S2 & $\mathrm{Z2}-\mathrm{S} 2$ & Z3-S2 & Z4-S2 & Z1-S3 & Z2-S3 & Z3-S3 & Z4-S3 & & & \\
\hline Horizontal Formwork & & Z1-S1 & $\mathrm{Z2}-\mathrm{S1}$ & Z3-S1 & Z4-S1 & Z1-S2 & Z2-S2 & Z3-S2 & Z4-S2 & Z1-S3 & Z2-S3 & Z3-S3 & Z4-S3 & & \\
\hline Horizontal Rebar & & Z1-S1 & $\mathrm{Z2}-\mathrm{S1}$ & Z3-S1 & Z4-S1 & Z1-S2 & Z2-S2 & Z3-S2 & Z4-S2 & Z1-S3 & Z2-S3 & Z3-S3 & Z4-S3 & & \\
\hline Horizonal Piping Installation & & & Z1-S1 & Z2-S1 & Z3-S1 & Z4-S1 & Z1-S2 & Z2-52 & Z3-S2 & Z4-S2 & Z1-S3 & Z2-S3 & Z3-S3 & Z4-S3 & \\
\hline Horizontal Electrical Installation & & & Z1-S1 & Z2-S1 & Z3-S1 & Z4-S1 & Z1-S2 & Z2-S2 & Z3-S2 & Z4-S2 & Z1-S3 & Z2-\$3 & $\mathrm{Z3}-\mathrm{S3}$ & $\mathrm{Z4-S3}$ & \\
\hline Horizontal Concrete Puring & & & & Z1-S1 & Z2-S1 & Z3-S1 & Z4-S1 & Z1-S2 & Z2-S2 & Z3-S2 & Z4-S2 & Z1-S3 & $\mathrm{Z2}-\mathrm{S3}$ & Z3-S3 & $\mathrm{Z4}-\mathrm{S} 3$ \\
\hline
\end{tabular}

Fig. 2: Takt-time schedule of structural work. Z1 (Zone 1)-S1 (Story 1).

Flowline represents the activity as a single line rather than the dual lines of the line of balance. The activities' relationships of a flowline are activity on node, whereas that of a line of balance are activity on arrow (AoA). Yet, another difference is seen on the vertical axis. In the line of balance, it represents the line of balance quantity, while in the flowline, it presents the location for the intended sequence for construction (Kenley and Seppänen 2010).

The flowline scheduling method can be applied in a building of highly repetitive processes. The flowline of each activity facilitates the comprehension of handoffs and milestones (Brioso 2015b). To make the flowlines, the planner must divide the project on location into three different levels. First, the location units are divided by story (level 1); second, by daily zones (level 2); and third, by subsectors or production units that are executed during the workday (level 3) (Brioso et al. 2016).

The flowline method is a visual tool that helps planners to understand the differences between the planned flowlines and the actual execution curves (Seppänen et al. 2010). One of the main purposes of the flowlines is to forecast, based on the execution slope, any possible inconvenience or failure of the workflow plan. Thus, managers can take early actions to reach the planned target (Seppänen et al. 2013). The flowline schedule in an Excel spreadsheet for the structural works is shown in Figure 3.

\subsection{Point-to-point precedence relations}

Precedence diagram method (PDM) was developed in the early 1960s for interpreting the CPM network. Levy et al. (1963) were correct in their theory and assessment that PDM means an activity-on-node network consisting of activities with given durations, assuming constant intensity and four types of logical relations (Finish-to-Start (FS), Start-to-Start (SS), Start-to-Finish (SF), and Finish-toFinish (FF)) between activities (Hajdu 2016). The activity is 


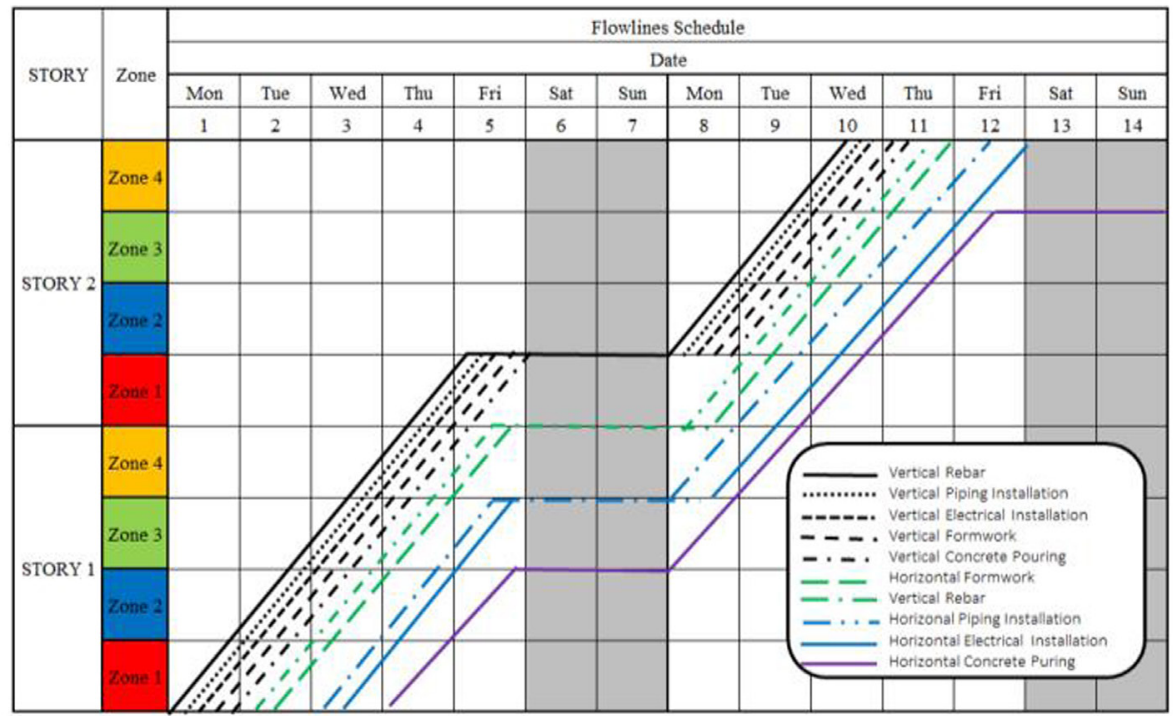

Fig. 3: Flowline schedule of the project.

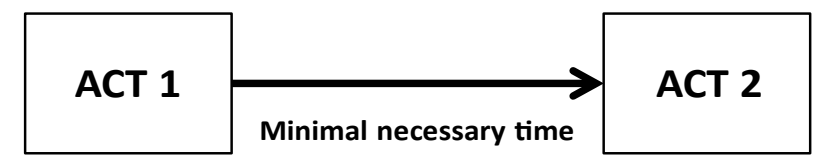

Fig. 4: Principle of precedence diagram method.

represented as a node connected to other activities by arrows linking two or more activities as shown in Figure 4. PDM was a very popular and interesting tool for users, which played an important role in the development of the CPM. It is the logical and visual tool that allowed quick recognition of the critical flow, i.e., the structure and sequence of activities.

PDM has hardly changed during the last few decades, despite the critiques voiced regarding its modeling capabilities. Traditional precedence relations are a subset of the point-to-point relations: in these cases, the end points of activities are connected, so that they can be referred to as endpoint relations (Hajdu 2015). Newly developed pointto-point relations are better from a theoretical and practical point of view than the solutions based on traditional precedence relationships, but they still cannot provide a theoretically perfect solution (Bokor and Hajdu 2015). Figure 5 shows an example of a PTPPR.

In a large-scale project with highly repetitive activities, the production system might be designed using one-day takt and four zones per story. Thus, planners can create the takt-time schedule accordingly. In addition, planners might create flowlines and PTPPR schedules with the same information due to the compatibility of the three methods. The key element is the division of activities in subactivities per location with FS0 precedence relationships, as shown in Figure 5.

\section{Case study development}

\subsection{Workshop design}

The mock-up project in this study is a three-story educational building in the city of Lima, Peru. In this case, the footprint area is $238 \mathrm{~m}^{2} / \mathrm{story}$. The construction processes are highly repetitive in each story. The structure works include (1) vertical rebar, (2) vertical piping installation, (3) vertical electrical installation, (4) vertical formwork, (5) vertical concrete pouring, (6) horizontal formwork, (7) horizontal rebar, (8) horizontal piping installation, (9) horizontal electrical installation, and (10) horizontal concrete pouring.

The workshops were led by one of the senior researchers, one research assistant, and one instructor. The research was conducted in 29 final year students of civil engineering at the PUCP in the course entitled "CIV284: Construction Planning." This course primarily provides an understanding of planning and scheduling through lectures, workshops, simulations, and discussion periods. Topics covered in the course include project integration management, project scope management, project time management, and project cost management.

\subsection{Workshop 1: Excel spreadsheets and 2D drawings}

Traditional tools such as Excel spreadsheets and 2D drawings are used to teach production system design with takt-time, flowlines, and PTPPR. Students are handed four different construction configurations (with different 


\begin{tabular}{|c|c|c|c|c|c|c|}
\hline \multirow{4}{*}{ STORY } & \multirow{4}{*}{ Zone } & \multicolumn{5}{|c|}{ Point to Point Precedence Relations } \\
\hline & & \multicolumn{5}{|c|}{ First Week } \\
\hline & & Mon & Tue & $\overline{\mathrm{Wec}}$ & Thu & Fri \\
\hline & & 1 & 2 & 3 & 4 & 5 \\
\hline \multirow{3}{*}{ STORY 2} & Zone 4 & & & & & \\
\hline & Zone 3 & & & & & \\
\hline & Zone 2 & & & & & \\
\hline \multirow{4}{*}{ STORY 1} & Zone 4 & & & & & \\
\hline & Zone 3 & & & & & \\
\hline & Zone 2 & & & & \multirow{2}{*}{\multicolumn{2}{|c|}{$\begin{array}{c}\text { A: Ceiling and Wall Sealing } \\
\cdots \cdots \cdot \text { B: Ceiling and Wall Screeding }\end{array}$}} \\
\hline & Zone 1 & & & & & \\
\hline
\end{tabular}

Fig. 5: Finishing activities using fragmentation and FSO relationships (adapted from the study by Hajdu (2015)).

Tab. 1: Set of construction alternatives to be used in the three workshops.

\begin{tabular}{lllllllll}
\hline Alternative & $\begin{array}{l}\text { Zones per } \\
\text { story }\end{array}$ & $\begin{array}{l}\text { Takt-time } \\
\text { (day) }\end{array}$ & \multicolumn{4}{c}{ Footprint } & $\begin{array}{l}\text { Days per } \\
\text { story }\end{array}$ \\
\cline { 4 - 7 } & & & $\begin{array}{l}\mathbf{Z 1} \\
\left(\mathbf{m}^{2}\right)\end{array}$ & $\begin{array}{l}\mathbf{Z 2} \\
\left(\mathbf{m}^{2}\right)\end{array}$ & $\begin{array}{l}\mathbf{Z 3} \\
\left(\mathbf{m}^{2}\right)\end{array}$ & $\begin{array}{l}\mathbf{Z} 4 \\
\left(\mathbf{m}^{2}\right)\end{array}$ \\
\hline 3A & 3 & 1 & 53 & 36 & 107 & - & 3 \\
3B & 3 & 1 & 90 & 80 & 67 & - & 3 \\
4A & 4 & 1 & 53 & 39 & 84 & 62 & 4 \\
4B & 4 & 1 & 76 & 55 & 62 & 45 & 4 \\
\hline
\end{tabular}

numbers of zones per story and different zone sizes). They then identify alternatives and analyze the four different construction options. For each alternative, they develop a takt-time, flowlines, and PTPPR schedules. Table 1 shows a set of construction alternatives.

\subsection{Workshop 2: 3D and 4D models with Revit and Navisworks}

A 3D model is created. 4D models are produced using Revit 2016 and Navisworks Manage 2016, integrating takttime schedules (Workshop 1) with the 3D Model. Again, four different construction options are laid out. For each alternative, a takt-time schedule and 4D Model are generated. It is important to highlight that foundations, rebar, and mechanical, electrical, and plumbing (MEP) systems were not modeled, owing to didactical considerations.

\subsection{Workshop 3: 4D and 5D models with Vico Office and Survey}

Vico Office is presented to the students and used for the automation of schedules and comparison of the takt-time and flowline methods. One of the flowlines schedules developed in the workshop is presented in Figure 6. Finally, a questionnaire was designed to capture students' perceptions on the methods and the software used. The survey was conducted at the end of the workshop.

Table 2 shows the sequence of the workshops, the tools used, and the tasks to be performed by the students in each stage.

\section{Results and discussion}

\subsection{Workshop 1: Excel spreadsheets and 2D drawings}

Initially, students analyzed the takt-time, flowline, and PTPPR information presented on Excel spreadsheets and 2D drawings. They then divided each story into zones or locations and designed the crews and materials needed to achieve a constant production flow. Nevertheless, students were not aware of the existence of clashes in the construction process because of the visual limitations inherent in 2D analysis. Students also had difficulties in creating flowlines - unlike with takt-time schedules, which are more easily created in Microsoft Excel. Finally, students paid more attention to visual management by the superposition of the PTPPR over the flowlines, simulating and comparing the planned work with the real work. An example of executed flowlines and PTPPR is shown in Figure 7.

\subsection{Workshop 2: 3D and 4D models with Revit and Navisworks}

Here, research assistants made a presentation on the 3D and 4D models that used the same information as the 


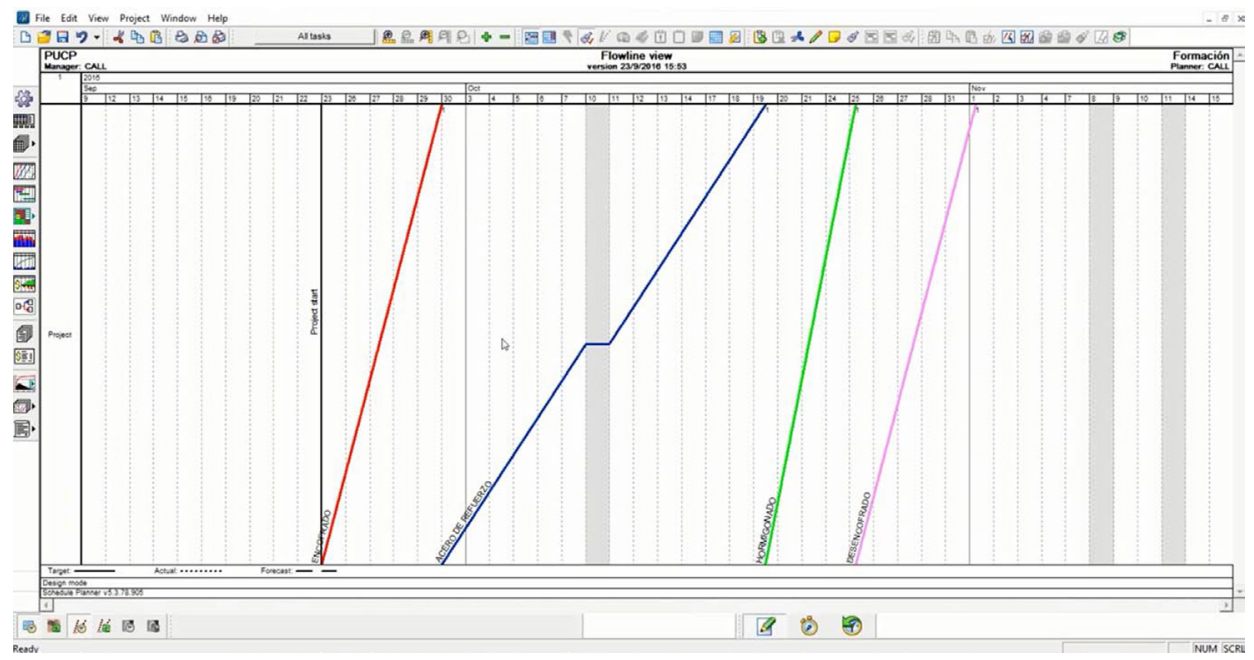

Fig. 6: Flowlines scheduling in Vico Office.

Tab. 2: Summary of the workshop design.

\begin{tabular}{|c|c|c|c|}
\hline & Scheduling methods & Tools & Tasks \\
\hline Stage 1 & $\begin{array}{l}\text { Takt-time, flowlines, } \\
\text { and PTPPR }\end{array}$ & 2D drawings and Excel spreadsheets & $\begin{array}{l}\text { Manual quantity takeoff } \\
\text { Manual design of crews } \\
\text { Use of Excel spreadsheets to create schedules } \\
\text { Simulation of planned vs. mock-up actual execution }\end{array}$ \\
\hline Stage 2 & Takt-time, flowlines & $\begin{array}{l}\text { 3D models, 4D models, Revit, and } \\
\text { Navisworks } 2016\end{array}$ & $\begin{array}{l}\text { Automatic extraction of quantitative takeoff } \\
\text { Visualize } 4 \mathrm{D} \text { models } \\
\text { Detect process clashes in the } 4 \mathrm{D} \text { model } \\
\text { Comparison with Stage } 1\end{array}$ \\
\hline Stage 3 & Takt-time, flowlines & $\begin{array}{l}\text { 3D models, } 4 \mathrm{D} \text { and } 5 \mathrm{D} \text { models, and } \\
\text { Vico Office }\end{array}$ & $\begin{array}{l}\text { Visualize } 4 \mathrm{D} \text { and } 5 \mathrm{D} \text { models } \\
\text { Automatic creation of schedules in Vico Office } \\
\text { Iteration of different crews changing data in 5D models } \\
\text { Comparison with Stages } 1 \text { and } 2\end{array}$ \\
\hline
\end{tabular}

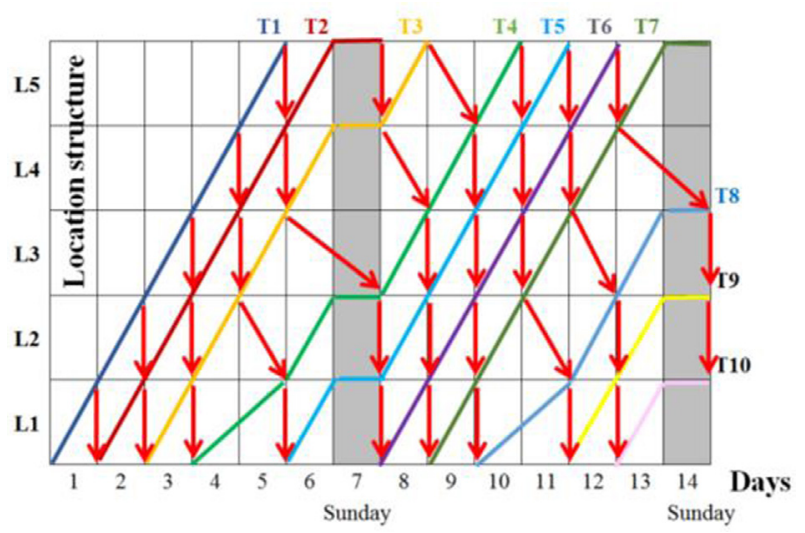

Fig. 7: Flowlines and point-to-point precedence relations (adapted from the study by Brioso et al. (2016)).

first stage. Students then visualized elements and the construction process. Even though the workshop helped them to gain new insights not allowed by traditional 2D drawings, the students also encountered some weaknesses of the 3D models. These include the following: (1) The 3D model is isolated. Whenever the takt-time schedule changes, all the related documents must be changed manually. (2) A 3D model for each construction alternative must be generated (splitting elements according to each zone's borders); otherwise, quantity takeoff for each alternative cannot be obtained properly. (3) It is not possible to integrate all project life cycle information into a unique 3D virtual model.

By using Navisworks, students perceived the strengths of a 4D Model for planning and scheduling. They understood the potential of 4D models in the industry, where planners and project managers frequently must deal with weak understandings and few visual tools. Students were aware that the takt-time schedules were developed separately and then linked to the 3D model. At this stage, it is not possible to visualize flowlines and PTPPR automatically from the 4D model in Navisworks. By the end of this 
workshop, students understood the strengths and weaknesses of 3D and 4D models compared to traditional 2D management. Figure 8 shows the 4D model of one alternative analyzed.

\subsection{Workshop 3: 4D and 5D models with Vico Office}

During the last workshop, students noticed that takttime activities, and flowlines could be related using a 5D model, in this case, using Vico Office. The main input to develop a 5D model is a previously made 3D model (Workshop 2). In this session, students realized how a 5D model integrates, in a unique virtual construct, all the planning and scheduling techniques and tools they had learned about during the course, and then easily link those elements with the cost. It was not an arduous task, due to the prior knowledge that allowed them to understand those processes, as evidenced in the results of the surveys.

Once the model was completed and shown to the students, the research assistants introduced them to all the available information that could be automatically generated from this model, among them, the takt-time activities and flowlines. Figure 9 shows the presentation, and Figure 10 shows the flowlines from Vico Office.

Likewise, students verified that each time that the 3D model or any element from the planning and cost section is modified, the 5D model is updated, and all the

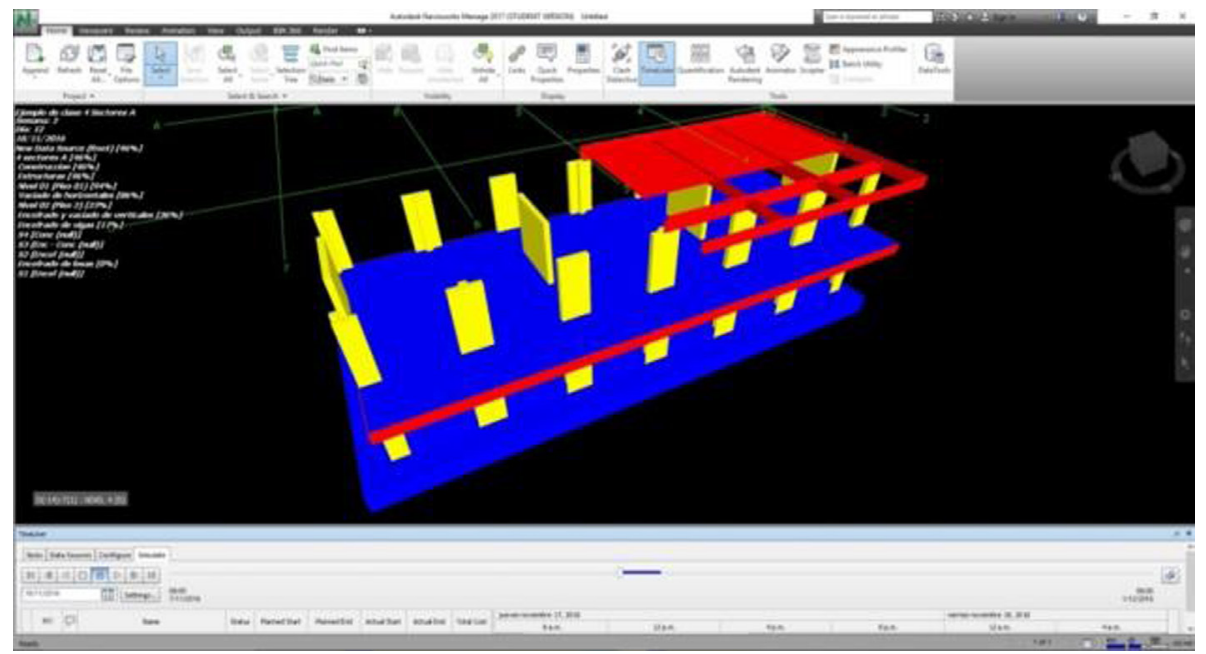

Fig. 8: 4D model of one alternative in Navisworks.

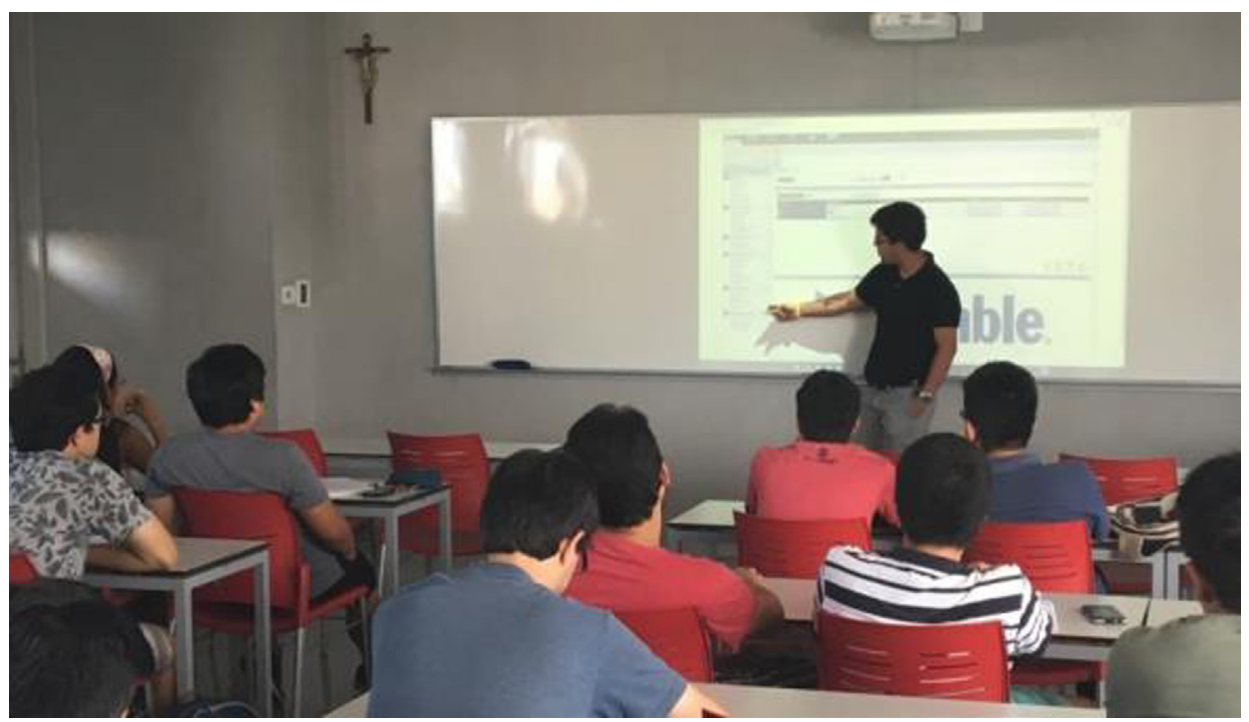

Fig. 9: Explanation of the workshop 3 with Vico Office. 


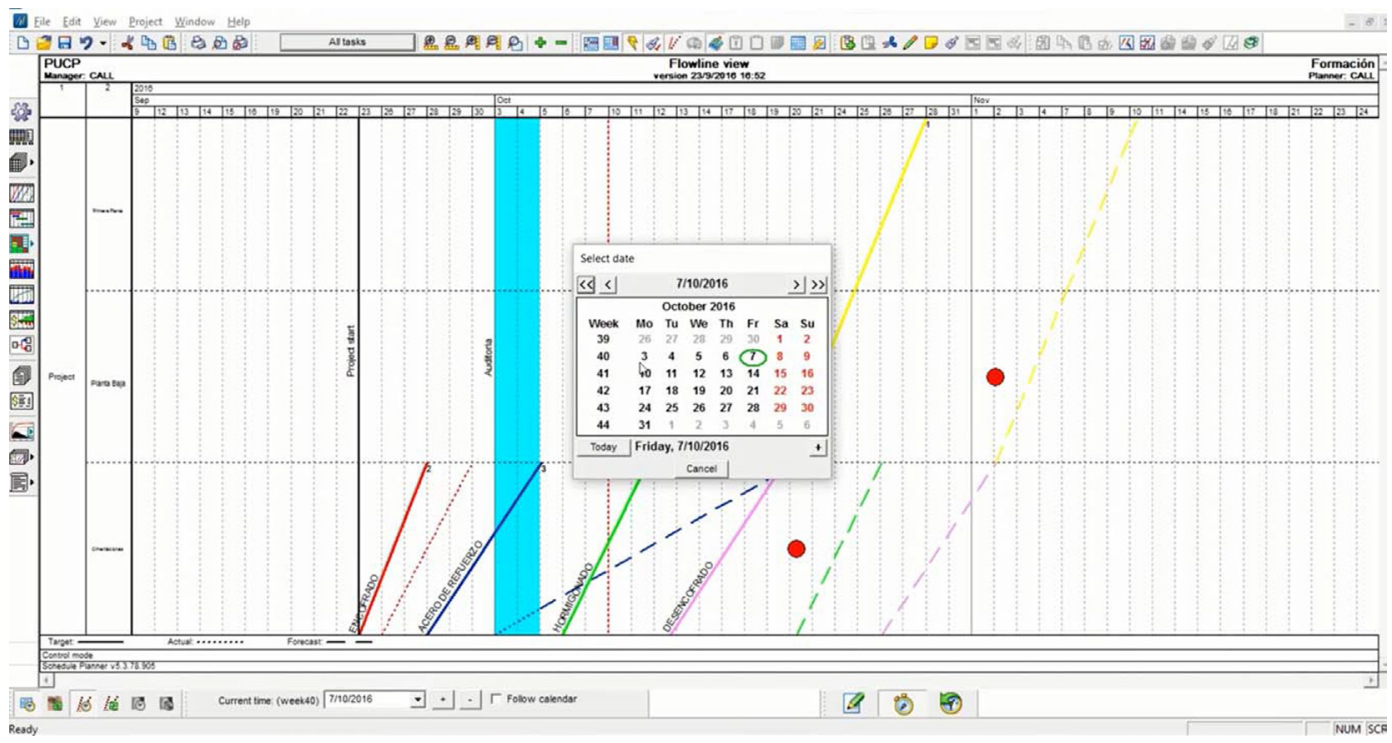

Fig. 10: Generation of flowlines.

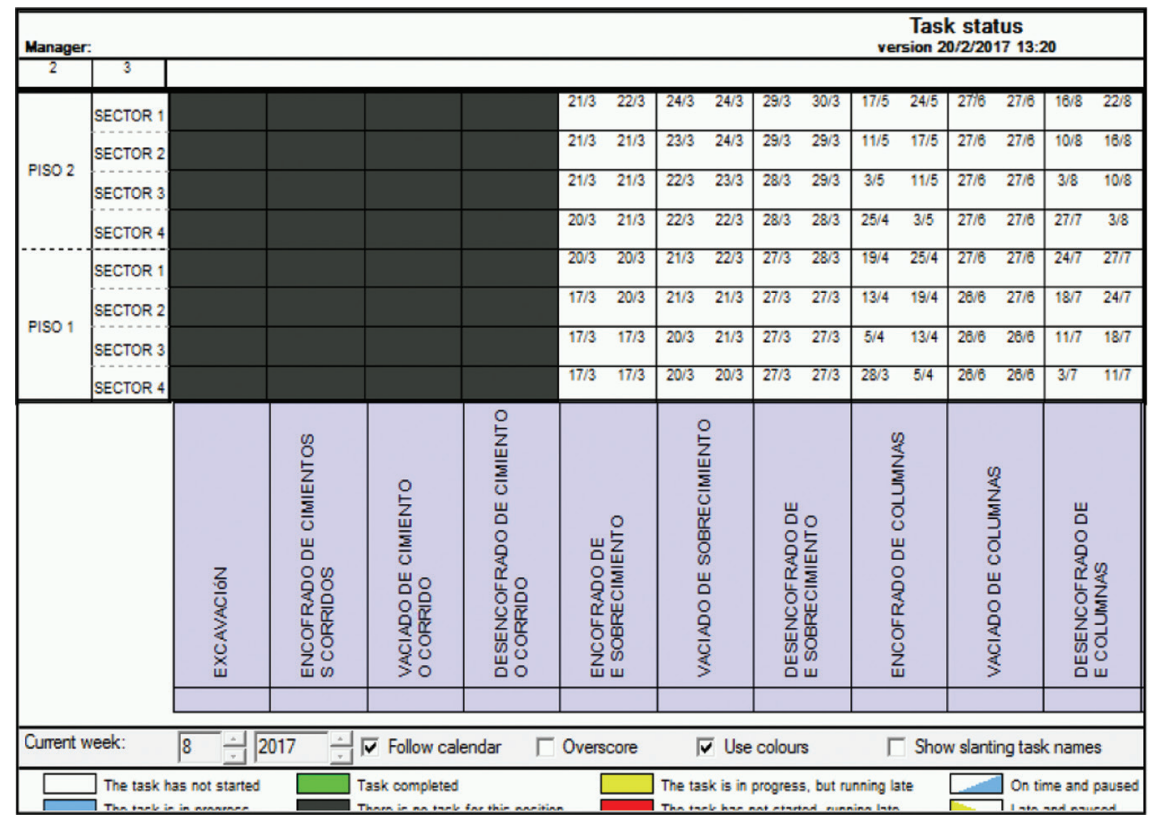

Fig. 11: Takt-time in Vico Office.

documents or outputs are also immediately modified. To generate the 5D model, costs must be added, so we used some commercial values for the activities selected to show how the planning and cost management are closely related in this virtual model. We explained different ways of making comparisons between initial costs and real or modified costs, and percentages of wastes, among others. The most valued benefits for the students were the following features: (1) the ability to access automated information, including the takt-time activities and flowlines; and (2) the relation between planning, scheduling, and cost management in a unique virtual model. The PTPPR is not automatically generated by Vico Office, but it is simple to develop over the flowlines from the model. Figure 11 shows one example of takt-time activities, and Figure 12 shows its $5 \mathrm{D}$ costs.

\subsection{Survey}

The survey was conducted at the end of the third workshop. Results are shown in Figure 13. 


\begin{tabular}{|c|c|c|c|c|c|c|c|c|c|}
\hline \multicolumn{2}{|c|}{ Code } & Description & Source Qty & Consumption & Consumption.. & Waste & Qty & UOM & Unit Cost \\
\hline Q & 000 & AUS 1 & 1.00 & 1.000 & 1.000 & 1.000 & 1.00 & & $204,229.26$ \\
\hline \multicolumn{2}{|c|}{-1} & SUBSTRUCTURE & 1.00 & 1.000 & 1.000 & 1.000 & 1.00 & & $78,831.00$ \\
\hline \multicolumn{2}{|c|}{1.1} & Excavation & 149.12 & 1.000 & 1.000 & 1.000 & 149.12 & M3 & 45.00 \\
\hline \multicolumn{2}{|r|}{-1.2} & Foundations & 1.00 & 1.000 & 1.000 & 1.000 & 1.00 & & $72,120.68$ \\
\hline & -1.2 .2 & Cimiento Corrido & 149.12 & 1.000 & 1.000 & 1.000 & $\begin{array}{l}149.12 \\
\end{array}$ & M3 & 265.10 \\
\hline & $1,2.2 .1$ & Formwork & 158.45 & 1.000 & 1.000 & 1.000 & 158.45 & M2 & 29.70 \\
\hline & 1.2 .2 .2 & Concrete & 149.12 & 1.000 & 1.000 & 1.000 & 149.12 & M3 & 233.54 \\
\hline & -1.2 .3 & Sobre Cimiento & 98.10 & 1.000 & 1.000 & 1.000 & 98.10 & M3 & 332.22 \\
\hline & 1.2 .3 .1 & Formwork & 154.00 & 1.000 & 1.000 & 1,000 & 154.00 & M2 & 32.32 \\
\hline & 1.2 .3 .2 & Concrete & 98.10 & 1.000 & 1.000 & 1.000 & 98.10 & M3 & 281.48 \\
\hline & -2 & \begin{tabular}{|l|} 
SUPERSTRUCTURE \\
\end{tabular} & 0.00 & 1.000 & 1.000 & 1.000 & 0.00 & & 0.00 \\
\hline \multirow[t]{4}{*}{ 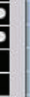 } & -2.1 & \begin{tabular}{|l|} 
Columns \\
\end{tabular} & 0.00 & 1.000 & 1.000 & 1.000 & 0.00 & EA & 0.00 \\
\hline & -2.1 .1 & Rectangular & 20.00 & 1.000 & 1.000 & 1.000 & 20.00 & EA & 367.16 \\
\hline & 2.1 .1 .1 & Formwork & 119.55 & 1.000 & 1.000 & 1.000 & 119.55 & M2 & 34.95 \\
\hline & 2.1 .1 .2 & Concrete & 11.50 & 1.000 & 1.000 & 1.000 & 11.50 & M3 & 275.13 \\
\hline \multirow[t]{3}{*}{ 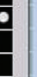 } & -2.1 .2 & L columns & 12.00 & 1.000 & 1.000 & 1.000 & 12.00 & EA & 435.10 \\
\hline & 2.1 .2 .1 & Formwork & 76.85 & 1.000 & 1.000 & 1.000 & 76.85 & M2 & 40.87 \\
\hline & 2.1 .2 .2 & Concrete & 7.56 & 1.000 & 1.000 & 1.000 & 7.56 & M3 & 275.13 \\
\hline \multirow[t]{3}{*}{ a } & -2.1 .3 & T Columns & 18.00 & 1.000 & 1.000 & 1.000 & 18.00 & EA & 630.76 \\
\hline & \begin{tabular}{|l}
2.1 .3 .1 \\
\end{tabular} & Formwork & 157.25 & 1.000 & 1.000 & 1.000 & 157.25 & M2 & 42.19 \\
\hline & 2.1 .3 .2 & Concrete & 17.15 & 1.000 & 1.000 & 1,000 & 17.15 & M3 & 275.13 \\
\hline & -2.2 & Walls & 10.00 & 1.000 & 1.000 & 1.000 & 10.00 & EA & $1,568.18$ \\
\hline & 2.2 .1 & Formork & 204.37 & 1.000 & 1.000 & 1.000 & 204.37 & M2 & 44.28 \\
\hline & 2.2 .2 & Concrete & 23.59 & 1.000 & 1.000 & 1.000 & 23.59 & M3 & 281.13 \\
\hline \multicolumn{2}{|r|}{-2.3} & Beems & 96.00 & 1.000 & 1.000 & 1.000 & 96.00 & EA & 370.34 \\
\hline & 2.3 .1 & Formwork & 486.36 & 1.000 & 1.000 & 1.000 & 486.36 & M2 & 39.05 \\
\hline & 2.3 .2 & Concrete & 63.66 & 1.000 & 1.000 & 1.000 & 63.66 & M3 & 260.15 \\
\hline \multicolumn{2}{|r|}{-2.4} & Slabs & 54.00 & 1.000 & 1.000 & 1.000 & 54.00 & EA & 843.33 \\
\hline & 2.4 .1 & Formwork & 597.21 & 1.000 & 1.000 & 1.000 & 597.21 & M2 & 30.97 \\
\hline \multirow{2}{*}{\multicolumn{2}{|c|}{-3}} & Concrete & 103.56 & 1.000 & 1.000 & 1.000 & 103.56 & & 261.15 \\
\hline & & Formwork removing & 1.00 & 1.000 & 1.000 & 1.000 & 1.00 & & $4,705.95$ \\
\hline
\end{tabular}

Fig. 12: Costs of the 5D model developed in Vico Office.



Fig. 13: Survey responses outline.

Students scored each question on the Likert Scale from 1 to 5 . A summary appears below.

- All students gave only the highest scores (4- mostly agree and 5 - definitely agree) to the following questions. The extreme values $\mathrm{w}$ ere (ix) (mean $=4.76$, standard deviation $(\mathrm{STD})=0.44)$ and $($ viii $)($ mean $=4.17, \mathrm{STD}=0.38)$. i. The 4D model allowed for improved visualization of the construction process.

ii. The 4D model allowed for improved visualization of the construction zones (locations).

iii. The 4D model allowed for the discovery of construction process clashes. 
iv. I am interested in learning more about building information modeling (BIM).

v. In general, I believe that this workshop was useful in helping me get a better understanding of sectorization using 4D models as opposed to the $2 \mathrm{D}$ drawing.

vi. Using VICO Office allows one to appreciate 4D (schedule, takt-time activities, and flowlines) and 5D models (+cost).

vii. PTPPR is useful for the visual management of the project.

viii. I would recommend that flowlines scheduling should include the PTPPR.

ix. I am interested in learning more about takt-time activities, flowlines, and PTPPR.

x. In general, I believe that this workshop was useful for helping me get a better understanding of sectorization using 4D and 5D models as opposed to the 2D drawings, Excel spreadsheets, and traditional software.

- The great majority agreed with the following:

i. Using the 4D model allowed for a greater appreciation of the differences in workloads between one location and another, in comparison to the 2D drawings.

ii. 4D model visualization in Vico Office (takt-time) allowed for the detection of construction process clashes.

iii. 4D model visualization in Vico Office (flowlines) allowed for the detection of construction process clashes.

From the latter comments, we concluded that students have long been interested in BIM 4D and 5D.

- Finally, we asked two interrelated questions and obtained the following result: (i) Are takt-time activities better than flowlines? $($ mean $=2.90$, STD $=0.72$ ); (ii) Are flowlines better than takt-time activities? (mean $=3.1$, STD $=0.72$ ). These values show that students do not perceive much advantage for one method compared to the other.

\section{Conclusions}

This research into teaching strategies suggests that the use of BIM+ models, such as 4D and 5D models, together with automated software, such as Vico Office, contributes to students' understanding of the concept and method of LPS using takt-time, flowlines, and PTPPR scheduling. The students identified some overlaps between the three methods, individual advantages, and their synergies and thus were able to select the most suitable one depending on the context (e.g., a linear project vs. a non-repetitive project) and the project stage (e.g., structural works or finishing). In addition, the use of advanced tools contributed to the selection of the best construction flow alternative, labor allocation, and materials workflow for a linear project.

First, the experience of making schedules with traditional tools and then looking at their digital presentations in BIM models allowed for significant understanding of BIM in 3D, 4D, and 5D models. Second, a more holistic understanding of the project scope and construction process was achieved by scrutinizing process clashes with digital models. Third, students were able to exemplify, visualize, and clarify any misunderstandings of Last Planner and BIM integration theory. Finally, the majority of the participants showed interest in learning more about the methods proposed in the workshops. The survey results show that students do not find significant differences between takt-time and flowlines. This suggests that they would be willing to use either one in the construction planning depending on the circumstances and project's characteristics. This view is shared by many scholars in the field.

In terms of programming and controlling, flowlines provide more information than takt-time schedules since locations are presented on the diagram, whereas PTPPR is maximized when flowlines are applied during project control. It is also recommended to integrate flowlines and PTPPR to improve visual management of construction scheduling and forecast possible problems related to productivity, resources allocation, and distribution of task per crew. Moreover, the use of PTPPR allow the students to visualize and easily understand how the activities are connected with their predecessor and thus to detect potential schedule deviations due to unstable productivity rates. This is represented by varying activity slopes and the length and slope of the arrows between the final and start of the next task on the same location. Finally, researchers suggest to incorporate simulations with non-linear projects to identify the most suitable scheduling method when complexity and variability is an issue. 


\section{Acknowledgments}

This study was partially funded by the Dirección de Gestión de la Investigación at Pontifical Catholic University of Peru and the Consejo Nacional de Ciencia, Tecnología e Innovación Tecnológica del Perú (CONCYTEC from its acronym in Spanish), according to the Convenio de Gestión $\mathrm{N}^{\circ}$ 232-2015-FONDECYT. We would also like to thank to Dilmer Dueñas, who kindly participated as instructor in the workshops.

\section{References}

Agrama, F. A. E. M. (2011). Linear projects scheduling using spreadsheets features. Alexandria Engineering Journal, 50(2), pp. 179-185.

Ballard, G. (2000). The last planner system of production control, Thesis. The University of Birmingham.

Ballard, G., \& Tommelein, I. (2016). Current process benchmark for the last planner system. Lean Construction Journal, 2016 Issue, pp. 57-89.

Bokor, O., \& Hajdu, M. (2015). Investigation of critical activities in a network with point-to-point relations. Procedia Engineering, 123, pp. 198-207.

Brioso, X. (2011). Applying Lean Construction to Loss Control. School of Civil Engineering, Engineering Department, Pontifical Catholic University of Peru, Lima, pp. 1-11.

Brioso, X. (2015a). Integrating ISO 21500 guidance on project management, lean construction and PMBOK. Procedia Engineering, 123, pp. 76-84.

Brioso, X. (2015b). Teaching lean construction: Pontifical Catholic University of Peru training course in lean project \& construction management. Procedia Engineering, 123, pp. 85-93.

Brioso, X., Humero, A., \& Calampa, S. (2016). Comparing point-to-point precedence relations and location-based management system in last planner system: A housing project of highly repetitive processes case study. Procedia Engineering, 164(June), pp. 12-19.

Dave, B., Hämäläinen, J.-P., Kemmer, S., Koskela, L., \& Koskenvesa, A. (2015). Suggestions to improve lean construction planning.
In: 23rd Annual Conference of the International Group for Lean Construction, Perth, Australia, pp. 193-202.

Frandson, A., Berghede, K., \& Tommelein, I. D. (2013). Takt time planning for construction of exterior cladding. In: Formoso, C.T., \& Tzortzopoulos, P. (eds.), 21st Annual Conference of the International Group for Lean Construction, Fortaleza, Brazil, 31-2 Aug 2013, pp. 527-536.

Hajdu, M. (2015). Point-to-point versus traditional precedence relations for modeling activity overlapping. Procedia Engineering, 123, pp. 208-215.

Hajdu, M. (2016). PDM time analysis with continuous and point-to-point relations: Calculations using an artificial example. Procedia Engineering, 164(June), pp. 57-67.

Kenley, R., \& Seppänen, O. (2010). Location-based management system for construction: Planning, scheduling, and control. Spon Press, London and New York, pp. 125-144.

Koskela, L. (1992). Application of the New Production Philosophy to Construction, CIFE Technical Report \#72, Department of Civil Engineering, Stanford University, Stanford, USA, pp. 30-37.

Lean Construction Institute. (2016). Available at http://www. leanconstruction.org/.

Levy, F. K., Thompson, G. L., \& Wiest, J. D. (1963). Introduction to the critical path method. In: Muth, G. L., \& Thompson, J. F. (eds.), Industrial Scheduling. Prentice-Hall, Englewood Cliffs, NJ (20), pp. 193-202.

Linnik, M., Berghede, K., \& Ballard, G. (2013). An experiment in takt time planning applied to non-repetitive work. In: Formoso, C. T., \& Tzortzopoulos, P. (eds.), 21st Annual Conference of the International Group for Lean Construction, 31-2 Aug 2013, Fortaleza, Brazil, pp. 546-555.

Murguía, D., Brioso, X., \& Pimentel, A. (2016). Applying lean techniques to improve performance in the finishing phase of a residential building. In: International Group for Lean Construction, Boston, USA, pp. 43-52.

Seppänen, O., Ballard, G., \& Pesonen, S. (2010). The combination of last planner system and location-based management system. Lean Construction Journal, 2010 Issue, pp. 43-54.

Seppänen, O., Evinger, J., \& Mouflard, C. (2013). Comparison of LBMS schedule forecasts to actual progress. In: 21st Annual Conference of the International Group for Lean Construction 2013 Fortaleza, Brazil, pp. 506-515.

Tommelein, I. D. (2017). Collaborative takt time planning of nonrepetitive work. In: Proceedings of 25th Annual Conference of the International Group for Lean Construction, (July), Heraklion, Greece, 9-12 Jul 2017, pp. 745-752. 